\title{
EVIDENCE-BASED CARE: AN INNOVATION TO IMPROVE NURSING PRACTICE GLOBALLY
}

\author{
I. I. AKPABIO AND E. U. DUKE \\ (Received 13 October 2014; Revision Accepted 16 January 2015)
}

\begin{abstract}
Evidence-Based Nursing (EBN) permits the highest quality of care in meeting the multifaceted needs of clients using the best available evidence from research findings, expert ideas from specialists in the various health care sectors and feedback from clients. However, in many instances, various challenges need to be addressed to enhance utilization of the best available evidence in nursing practice. This paper focused on ways of identifying the acceptable evidence and where they could be found; methods of implementing EBN; and appropriate measures of supporting EBN practice. For improved practice, it is recommended that nursing education should increasingly focus on development of skills for critical thinking and reflective practice as well as promotion of mentorship among nurse educators and nurse clinicians in regards to implementation of available and acceptable evidence.
\end{abstract}

KEYWORDS: Evidence-based-care; Nursing; Practice.

\section{INTRODUCTION}

Evidence-Based Nursing (EBN) is the process by which nurses make clinical decisions using the best available research evidence, their clinical expertise and patients' preferences (Stephens and Cassidy, 1999). This definition implies that with EBN, practice is guided not only by evidence from research findings but also from specialists in the various health care sectors and feedback from clients usually from their preferences. The focus is on resolving nursing problems based on accurate analysis of existing information.

The idea of evidence-based practice for nursing has grown out of the evidence-based medicine movement, which requires the integration of the best research evidence with clinical expertise and patients' unique values and circumstances (Straus, Richardson, Glasziou and Haynes, 2005). It permits the highest quality of care in meeting the multifaceted needs of patients and families.

As a process, EBN involves identification of facts or scientific evidence, appraising or analyzing the evidence and thereafter applying the evidence in nursing interventions. Evidence-based practice is inextricably linked with the nursing process. All the steps of the nursing process, which include: Assessment; Nursing diagnoses; Outcome identification; Planning of care; Implementation of care and Evaluation of care outcome (Smeltzer, Bare, Cheever and Hinkle, 2004) involve utilization of the best available evidence.

Identifying the need for focus on EBN practice, Akpabio (2010) documented the following among other reasons:

i. Clients are becoming more sophisticated in their demands for nursing care based on the best practice evidence. There is therefore the need to meet their demands if nursing should be responsive and accountable to the people served. This feature is one of the characteristics of a profession.

ii. Nurses and other professionals daily confront questions about assessment, treatment and prevention. These all require the best practice guided by evidence to improve clients' behavior, physiologic and psycho-social parameters.

iii. There is usually the need to validate some aspects of practice to evaluate how they contribute to health.

iv. As health care costs continue to rise, there should be emphasis to provide care based on the best available evidence to prevent wastages, preserve resources and reduce costs.

Thus, as important as the practice of nursing that is based on evidence could be, there are however contending issues that should be addressed for success to be achieved. As a fairly new concept, Stetler, Brunnel, Giuliano, Morsi, Prince and Newell-Stokes (2008) asserted that its meaning is not always clear, nor is its full implication for nurse practitioners and administrators explained. However a pragmatic definition by the authors shows EBN to involve a process of integrating individual clinical expertise (proficiency and judgment that is acquired through clinical experience and practice) with the best available external clinical evidence from systematic research. In many instances, the issues that should be addressed and, which are the focus of this paper include:

i. The acceptable evidence and where they could be found

I. I. Akpabio, Department of Nursing Science, University of Calabar, P. M. B.1115, Calabar, Cross River State, Nigeria

E. U. Duke, Department of Nursing Science, University of Calabar, P. M. B.1115, Calabar, Cross River State, Nigeria 
ii. How the evidence should be appraised and related to practice (Methods of implementing EBN)

iii. How EBN should be supported

\subsection{Accessing the best (Acceptable) evidence to guide practice}

According to Goding and Edwards (2002), evidence-based practice has often been adopted within nursing, midwifery and health visiting without careful consideration of the nature of such evidence. Acceptable evidence involves access to information on what works, to allow professionals in conjunction with clients to select treatments that are most likely to be helpful and non-harmful before treatment is begun (Melnyk and Fineout-Overholt, 2005). Furthermore, as earlier indicated, available and acceptable evidence could involve research evidence, evidence from clinical expertise and clients' preferences, which have been appraised and adjudged to have potential benefits to health and wellbeing of consumers of health care or nursing services. From this later explanation, it could be obvious that many of the evidence that should have been categorized as acceptable could have been missed due to poor documentation of many aspects of nursing care.

\subsubsection{Research or empirically supported evidence}

Research or empirically supported practice refers to preferential use of physical, mental and social or behavioural health interventions for which systematic empirical research has provided evidence of statistically significant effectiveness as treatment or care for specific problems or health situations (Melnyk and FineoutOverholt, 2005). In recent years, research has been proposed to be an integral part of nursing but in practice, this expectation is far from being achieved since there is still a wide gap between research findings and actual implementation of research findings.

According to John (2011), research is expected to provide valuable, objective and factual knowledge for rational decision-making and promotion of EBN practice. In assessing quality and strengths of evidence from empirical studies, Registered Nurses' Association of Ontario (2004) asserted that evidence could vary depending on how vigorous and comprehensive the process of research was. The categories identified included the following:

Level 1: Evidence obtained from controlled experimental studies

Level 2: Evidence obtained from Quasi-experimental studies

\section{Level 3: Evidence obtained from comparative studies}

In its usage, it could be stated that controlled experimental studies are more valuable in determining causes and effects relationship whenever the use of the method could be feasible and ethically acceptable.
1.2.2. Evidence from clinical expertise and patients' preferences

Nursing involves complex, intangible human behavior that demands interpretive holistic approach of obtaining perceptions rather than a reductionist approach (Goding and Edwards, 2002). Furthermore, nursing has a strong tradition of focusing on various ways of 'Knowing', to provide excellent care. Carper (1978) identified four fundamental patterns of 'Knowing' in nursing to include empirical, ethics, personal and aesthetic patterns.

Thereafter, Fawcett, Watson, Neumann, Walker and Fitzpatrick (2001) updated and applied Carper's theory to provide further statements on nurses' sources of knowledge. In their assertion, empirical knowing relates to factual descriptions, explanations and predictions as earlier indicated under research or empirically supported practice. Ethical knowledge refers to moral obligations, values and desired ends; personal knowing pertains to the genuine transpersonal relation between each nurse and each patient while aesthetic knowing shows the nurses' perception of what is significant in the patients' behavior and also addresses the artful performance of nursing skills and ways of being. The aforementioned sources of acquiring, processing, reflecting and evaluating nursing knowledge are important in gaining acceptable clinical expertise and evidence for nursing practice provided that the experiences are documented for instance in case reports or as expert opinions.

Continuous acquisition and promotion of ethical, personal and aesthetic knowledge for evidence-based practice involves the process of lifelong, self-directed learning in which caring for patients creates the need for clinically important information about diagnoses, prognoses, therapy and other clinical and health care issues; and in which practitioners convert acquired information needs into answerable questions. Secondly, there is need to track down with maximum efficiency the best evidence, with which to answer clinical questions whether from the clinical examination, the diagnostic laboratory or other relevant sources. Thirdly, clinical information acquisition should involve critically appraising the clinical evidence for validity (Closeness to the truth) and usefulness (Clinical applicability). Fourthly, the appraised clinical expert information could be applied in practice and lastly, the performances should be evaluated for effectiveness (Sackett, 1997).

Reporting further on the best evidence, Akpabio and Ebong (2010) argued that good evidence could be described as the body of information that has been evaluated or analyzed to fit best into the situation for which intervention is needed. In their assertion, the definition of 'good evidence' may be difficult to produce especially in the health sector with the need to resolve very complex problems. Nurses are committed to providing holistic care, treating and working with clients under diverse conditions. In many instances, the factors that need to be considered vary from one situation to another or are perceived differently by different individuals. The aforementioned factors indicate 
therefore that the best evidence in one situation could be unacceptable at another of similar situation. The best evidence may therefore not simply be one piece of research finding but could involve information from various sources. Tracking down the best evidence for practical application in nursing practice and education therefore requires skills including critical thinking ability by nurses to be able to appraise the available evidence. This aspect is vital if EBN is to serve the purpose of improving practice.

\subsection{Implementation of EBN}

Utilization of evidence in nursing practice does not imply the application of any available information. According to Kitson, Harvey and McComack (1998), successful implementation of research in practice is a function of three core elements including the level and nature of the evidence, the context or environment into which the research is to be implemented and the method in which the process is facilitated. Explaining further on evidence-based practice implementation, Polit and Beck (2005) identified three broad criteria that are important prior to research result utilization. These include clinical relevance of the research findings corresponding to the level and nature of the evidence as earlier indicated by Kitson, Harvey and McComack (1998) scientific merit and implementation potential.

1.3.1. Clinical relevance involves the significance or benefits, which the study findings will bring to resolving nursing problems. In Tanner's (1987) assertion, five questions could be used in evaluating the clinical relevance of a research. These are:

i. Potential to solve current problems experienced in practice

ii. Ability to contribute to clinical decision-making

iii. Results obtained through appropriate statistical assessment

iv. Ability of nurse practitioners to exercise control over the implementation of the interventions

v. Ability to use the measures in the study in clinical practice

It is envisaged that if the responses to the five questions are negative, there is little or no prospect of clinical relevance with regards to the research findings.

1.3.2. Scientific merit: Apart from identifying that the research findings and conclusions are accurate, believable and appropriate for generalization, scientific merit of a research work also involves the issue of replicating the study in a new setting with a new sample of study participants with the likelihood of obtaining similar evidence (Kerlinger, 1986) In the author's estimation, at least one and ideally more of the studies should have been conducted in a clinical setting with real clients.

1.3.3 Implementation potential: Although research findings could have clinical relevance and scientific merits, implementation potentials could be lacking. Several factors are involved in regards to implementation potentials, which could be grouped under three domains: Transferability; Feasibility and Cost/Benefit ratio (Tanner, 1987) taking into consideration the context or environment into which the research is to be implemented.

Relating evidence to practice should involve systematic and organized steps of implementation. Stephens and Cassidy (1999) documented four steps, which are similar to those conceptualized by Rosenberg and Donald (1996). These include:

i. Clear identification of nursing problems based on accurate analysis of current nursing knowledge and practice.

ii. Systematic search and collection of relevant literature appropriate to resolve the problem

iii. Evaluating or appraising available evidence using established criteria regarding scientific merit and implementation potential.

iv. Selecting interventions based on the most valid evidence.

Furthermore, if nursing practice should derive its impetus from a sound body of knowledge or evidence, findings of studies documented in literature should be critically appraised. One way of doing this is critique of research reports. Berman, Snyder, Kozier and Erb (2008) asserted that a research critique involves intensive scrutiny of a study including its strengths and weaknesses, statistical and clinical significance and the possibility of generalizing the results to a target population. A research critique according to Akpabio (2010) enhances the ability of the nurse to evaluate the scientific merit of the study and decide how the results may be useful in practice.

Measures of appraising research results documented in literature include substantive and theoretical dimensions, methodological dimensions, ethical dimensions, interpretive dimensions and presentation or stylistic dimensions (Polit and Beck, 2005). Following the appraisal, irrelevant details should be excluded while important details should receive appropriate focus to reflect the scientific requirement for evidence-based practice.

\subsection{Measures of enhancing evidence-based nursing practice}

i. Nursing education should increasingly focus on development of skills for critical thinking and reflective practice. The elements of reflective decision-makers include adaptations and innovations, holistic perspective in care giving, social responsiveness, and accountability for services provided, self evaluation and focus on professional growth. Reflective decision-makers contemplate possible long-term consequences of professional actions, judge the appropriateness of the actions and the effects of the actions on clients' recovery and satisfaction with care as well as maintaining informed perspectives concerning all aspects of teaching and practice

ii. The nursing process should form the focus of nursing practice in all practical situations. The use of nursing process could stimulate nurse practitioners to look for ways of providing care using the best available evidence. 
iii. There is need to formulate supporting policies to promote EBN practice by government at all levels including Federal, State and Local.

iv. Nurse researchers should be encouraged to work in close collaboration with nurse clinicians in the practice areas where they could guide and influence decision-making and policy formulation as they relate to implementation of evidence-based practice. In that way, they could easily act as mentors to new and not well experienced researchers in the practice arenas, thus assisting them to develop better research skills. Furthermore, this initiative could bridge the gap between nurse practitioners in the practice arena and nurse educators in institutions of higher learning, thus promoting research in the relevant clinical areas and ability to translate research findings into practice.

v. There is need to create units in each health institution to develop guidelines for implementation of evidence-based practice. Such groups could carefully access and appraise research reports and thereafter formulate guidelines for practice.

vi. Collaboration with all stakeholders for health services research could promote awareness and avenues for implementation of research findings. For this reason, there is need for improvement in team work among the various care givers.

vii. Research reports should be widely circulated to all stakeholders including patients/clients. This could improve their attitudes and willingness to support implementation of new evidence.

\section{CONCLUSION}

Incorporating evidence into an organization's policies and procedures could raise several issues. Numerous small studies have been published in nursing literature but evaluating studies for scientific merit could be an intimidating task. In some cases, published guidelines could help reflect national standards and minimize the task. Furthermore, although policies could be changed to reflect current guidelines developed for implementation of the evidence, another critical issue could be the actual change in nursing practice to reflect the evidence.

To bridge the gaps between scientific evidence and patients' care, there is need for an in-depth understanding of the barriers and incentives to achieving changes in practice. Various theories and models for change point to a multitude of factors that may affect the successful implementation of evidence. When planning complex changes in practice, potential barriers at the various levels need to be addressed. Planning needs to take into account the nature of innovation, characteristics of the professionals and patients or clients involved; the social, organizational, economic and political context into which the changes are to be affected.

\section{REFERENCES}

Akpabio, I. I and Ebong, F. S., 2010. Research methodology and statistics in health and behavioural sciences, Calabar: Eclait Biz

Berman, A., Snyder, S. J., Kozier, B and Erb, G., 2008. Fundamentals of nursing: Concepts, process and practice, (8 ed.), New Jersey: Pearson, Prentice Hall.

Carper, B., 1978. Fundamental patterns of knowing: knowledge development for a practice discipline, At: www.nottingham.ac.uk/nursing/students/gnc/mo dels/Nur....

Centre for Disease Control and Prevention., 2001. Building capacity, technology transfer efforts and sustainability for HIV/AIDS' prevention, National Centre for HIV, STD and TB Prevention Programme Briefing.

Fawcett, J., Watson, J., Neuman, B., Walker, P. H and Fitzpatrick, J. J., 2001. On nursing Scholarship, Journal of Nursing Scholarship, 33, (2): 115 -119.

Goding, L and Edwards, K., 2002. Evidence-based practice, Nurse Researcher, 9, (4): 45-57.

Grol, R and Wensing, M., 2004. Barriers to evidencebased practice, The Medical Journal of Australia, 180, (6 suppl.): 557-60.

John, M. E., 2001. Improving access and quality of nursing care in Nigeria through research and collaboration, Keynote address presented at the annual conference of Nigerian Association of University Nursing Programmes (NAUNP) at the School of Nursing, Babcock University, IllishanRemo, Ogun State, Nigeria

Kerlinger, F., 1986. Foundations of behavioural research ( $3^{\text {rd }}$ ed.), New York: Holt Rinehart and Winston.

Kitson, A., Harvey, G and McComack, B., 1998. Enabling the implementation of evidence-based practice: A conceptual framework, Quality Health Care, 7: $149-158$.

Melnyk, B. M and Fineout-Overholt, E., 2005. Evidencebased practice in Nursing and Healthcare: $A$ guide to the best practice, Philadelphia, P. A.: Lippincott, Williams \& Wilkins.

Metherly, I and Titler, M. G., 2005. Implementing evidence-based practice: Evidence-based nursing practice, Medscape Today, Society for Urologic Nurses and Associates, At:www.medscape.com/viewarticles/514532-2. 
Polit, D. F and Beck, C. T., 2005. Essentials of Nursing Research: Methods, appraisal and utilization $\left(6^{\text {th }}\right.$ ed.), Philadelphia: Lippincott, Williams and Wilkins.

Registered Nurses' Association of Ontario., 2004. Best practice guideline for the Subcutaneous administration of insulin in adults with type 2 diabetes, Toronto: Registered Nurses' Association of Ontario.

Restas, A., 2000. Barriers to using research evidence in nursing practice, Journal of Advanced Nursing, 31, (3): $599-606$.

Rosenberg, W and Donald, A., 1996. Evidence-based medicine, United Kingdom: British Medicine Journal, 310

Sacket, D. L., 1997. Evidence-based medicine, Seminars in Perinatology, 21, (1): $3-5$.

Stephens, I and Cassidy, E., 1999. Evidence-based teaching: Current research in nursing Education, Norwalk C. T.: Appleton and Lange.

Stetler, C. B., Brunell, M., Giuliano, K. K., Morsi, D.,

Prince, L and Newell-Stokes, V., 2008. Evidence-based practice and the role of nursing leadership, Journal of Nursing Administration, 28, (7 - 8): 45 -53 .

Straus, S. E., Richardson, W. S., Glasziou, P and

Haynes, R., 2005. Evidence-Based Medicine: How to practice and teach. EBM ( $3^{\text {rd }}$ ed.), Edinburg, New York: Elsevier, Churchill Livingstone.

Tanner, C. A., 1987. Evaluating research for use in practice: Guidelines for the clinician, Heart and Lung, 16, $424-43$. 